\title{
Gene therapy for human ovarian cancer cells using efficient expression of Fas gene combined with $\gamma \delta \mathrm{T}$ cells
}

\author{
JIAJING LIN ${ }^{1 *}$, DINGYUAN ZENG ${ }^{2 *}$, HONGYING HE $^{1}$, GUANGPING TAN ${ }^{1}$, \\ YING LAN ${ }^{3}$, FUYAN JIANG ${ }^{4}$ and SHUTING SHENG ${ }^{5}$

\begin{abstract}
${ }^{1}$ Department of Gynecology, The 4th Hospital Affiliated to Guangxi Medical University, Liuzhou, Guangxi 545005;
${ }^{2}$ Department of Gynecology, Maternity and Children's Hospital Affiliated to The Guangxi University of Science and

Technology; ${ }^{3}$ Department of Gynecology, 1st Hospital Affiliated to Guangxi University of Science and Technology, of Gynecology, Liuzhou Hospital of Traditional Chinese Medicine, Liuzhou, Guangxi 545001, P.R. China
\end{abstract} \\ Liuzhou, Guangxi 545002; ${ }^{4}$ Department of Gynecology, Liuzhou Tumor Hospital, Liuzhou, Guangxi 545005; ${ }^{5}$ Department
}

Received February 10, 2016; Accepted April 27, 2017

DOI: $10.3892 / \mathrm{mmr} .2017 .7107$

\begin{abstract}
Low tissue specificity and efficiency of exogenous gene expression are the two major obstacles in tumor-targeted gene therapy. The Fas cell surface death receptor (Fas)/Fas ligand pathway is one of the primary pathways responsible for the regulation of cell apoptosis. The aim of the present study was to explore whether the regulation of tumor specific promoters and a two-step transcriptional amplification system (TSTA) assured efficient, targeted expression of their downstream Fas gene in human ovarian cancer cells, and to assess the killing effect of $\gamma \delta$ T cells on these cells with high Fas expression. Three shuttle plasmids containing different control elements of the human telomerase reverse transcriptase (hTERT) promoter and/or TSTA were constructed and packaged into adenovirus 5 (Ad5) vectors for the expression of exogenous Fas gene. The human ovarian cancer cell line SKOV3 and a control human embryonic lung fibroblast cell line were transfected with Ad5-hTERT-Fas or Ad5-hTERT-TSTA-Fas. Fas mRNA and protein expression were examined by reverse transcription-quantitative polymerase chain reaction and western blot analysis. $\gamma \delta \mathrm{T}$ lymphocytes were isolated, cultured and mixed at different ratios with SKOV3 cells with Fas expression in order to assess the killing effect of $\gamma \delta T$ cells. hTERT promoter induced the specific expression of FAS gene in SKOV3 cells, and the TSTA strategy increased FAS expression by 14.2-fold.
\end{abstract}

Correspondence to: Mr. Dingyuan Zeng, Department of Gynecology, Maternity and Children's Hospital Affiliated to The Guangxi University of Science and Technology, 50 Yingshan Road, Liuzhou, Guangxi 545002, P.R. China

E-mail: balianji804402@sohu.com

*Contributed equally

Key words: gene therapy, ovarian cancer, FAS gene, tissue-specific promoter, two-step transcriptional amplification
The killing effect of $\gamma \delta \mathrm{T}$ cells increased with the expression level of Fas and the effector-target cell ratio. The killing rate for SKOV3 cells with high FAS expression was $72.5 \%$ at an effector-target cell ratio of 40:1. The regulators of hTERT promoter and TSTA assure the efficient and targeted expression of their downstream Fas gene in SKOV3 cells. The killing effect of $\gamma \delta \mathrm{T}$ cells for ovarian cancer cells with relatively high Fas expression was improved.

\section{Introduction}

Low tissue specificity and efficiency of exogenous gene expression are the two major obstacles in tumor-targeted gene therapy. It is possible to achieve specific and efficient expression of a target gene in tumor cells by the regulation of tumor-specific promoters (TSP) and two-step transcriptional amplification (TSTA) (1,2). Multiple promoters have been used in targeted gene therapy for ovarian cancer, including secretory leukocyte protease inhibitor (SLPI), the ovary-specific promoter OSP1 and the human epithelial tissue-specific promoter, transcription factor HES1. However, these promoters are neither ovarian cancer-specific nor epithelial-specific, and are often active in normal cells (3). The human telomerase reverse transcriptase (hTERT) promoter is only activated in ovarian cancer cells exhibiting high telomerase activity, and therefore is a good candidate TSP for gene therapy to treat ovarian cancer.

The selection of efficient target genes and vectors is crucial for gene therapy. The Fas cell surface death receptor (Fas) gene promotes cell apoptosis through multiple pathways. The $\mathrm{FaS} / \mathrm{FaS}$ ligand (FasL) pathway is associated with not only the occurrence and development of cancer but also the chemosensitivity of cancer cells to certain chemotherapy reagents (4). Furthermore, since the FaS/FasL pathway is one of the primary pathways responsible for the regulation of cell apoptosis, immune effector $\gamma \delta$ T cells expressing FasL specifically target and kill cells expressing Fas. However, Fas is expressed at low levels or is not expressed at all in certain ovarian cancer cells, leading to reduced Fas-mediated cell apoptosis and drug resistance of these cells. Increasing the intracellular Fas level 
may be an efficient approach for gene therapy to treat ovarian cancer. Nevertheless, the exogenous gene is often expressed at low levels at target tumor sites.

In the present study, recombinant adenoviral vectors Ad5-hTERT-Fas and Ad5-hTERT-TSTA-Fas expressing Fas under the regulation of the hTERT promoter and a TSTA system were constructed in order to study the regulation of the hTERT promoter and TSTA system on Fas expression in the human ovarian cancer cell line SKOV3. The effect of $\gamma \delta T$ cells on SKOV3 cells with Fas expression was also studied at different effect-target cell ratios.

\section{Materials and methods}

Materials. The plasmids pBCVP2G5-luc-NSN, carrying galectin 4 (GAL4)VP2 fusion protein and G5E4TATA elements, and pBTdel279, carrying the hTERT core promoter, were provided by Dr. Yue Song, ShengJing Hospital of China Medical University (Shenyang, China). The plasmid vector pMD18-T was purchased from Takara Biotechnology Co., Ltd. (Dalian, China). The shuttle plasmid pDC316 and recombinant adenovirus backbone plasmid pBHGloxde1E13cre were purchased from Applied Genetic Technologies Corporation (Alachua, FL, USA). The AdEasy adenoviral vector systems were purchased from Applied Biological Materials, Inc. (Richmond, BC, Canada). The HEK293 cells used for co-transfection were purchased from Applied Genetic Technologies Corporation. Antibodies used for the detection of $\gamma \delta \mathrm{T}$ cell subsets and anti-human FasL-IgG1 monoclonal antibody (catalog no. MA5-17073) were purchased from eBioscience, Inc. (San Diego, CA, USA). Reagents for western blot analysis were purchased from Applygen Technologies, Inc. (Beijing, China). The antibodies used for western blotting were a mouse anti-human Fas monoclonal antibody (Abcam, Cambridge, UK; catalog no. $15285 ; 1: 500)$ and a $\beta$-actin monoclonal antibody (Abcam; catalog no. ab8226; 1:1,000). The quantitative real time-polymerase chain reaction (PCR) kit was purchased from Takara Biotechnology Co., Ltd.

Cell lines. The human ovarian carcinoma cells (SKOV3) and the control human embryonic lung fibroblast cells (HELF) were purchase from the Type Culture Collection of the Chinese Academy of Sciences (Shanghai, China). SKOV3 and HELF cells were cultured in Dulbecco's modified Eagle's medium, Invitrogen; Thermo Fisher Scientific, Inc. (Waltham, MA, USA) with $10 \%$ fetal bovine serum (FBS; Invitrogen, Thermo Fisher Scientific, Inc.) and $100 \mathrm{U} / \mathrm{ml}$ penicillin and streptomycin (Invitrogen; Thermo Fisher Scientific, Inc.). Cells were incubated at $37^{\circ} \mathrm{C}$ in a humidified atmosphere of $5 \% \mathrm{CO}_{2}$.

Construction of recombinant plasmid vectors carrying the hTERT promoter and/or TSTA regulatory elements and the Fas gene. pBCVP2G5-luc-NSN, pBTdel279, pCDNA3-Fas carrying the Fas gene and the shuttle plasmid pDC316 were transfected into JM109 Escherichia coli competent cells (Sigma Aldrich; Merck KGaA, Darmstadt, Germany) using the Lipofectamine ${ }^{\circledR} 3000$ (Invitrogen; Thermo Fisher Scientific, Inc.) according to the manufacturer's protocol. Following amplification, the bacterial plasmids were extracted and purified using the Wizard Plus SV Minipreps DNA Purification
System (Promega Corporation, Madison, WI, USA). Verification of pBTdel279 was performed using plasmid DNA as a template, and target fragments were sequenced using the primer pair 5'-TTG ATA TCG ACC CCC GGG TCC GCC CGG AGC A-3' and 5'-CTG AAT TCG CTG CCT GAA ACT CGC GCC GCG AG-3' containing EcoR V/EcoR I restriction enzyme sites. Verification of pCDNA3-Fas was performed using plasmid DNA as a template and the $\mathrm{T} 7$ promoter sequence 5'-TAA TAC GAC CTA CTA TAG GG-3' as a primer. Starting prior to the insertion site of the Fas gene, the target fragment was sequenced using the terminal ending method. At the same time, given that the insertion of Fas gene has Xba I and Kpn I enzyme sites, a fragment of $\sim 1,000$ bp was obtained following Xba I (catalog no. R0145, New England BioLabs, Inc., Ipswich, MA, USA) and Kpn I enzyme (catalog no. R0142; New England BioLabs, Inc.) digestion. Verification of pBCVP2G5-luc-NSN was performed as follows: Analysis of the plasmid profile revealed that it is possible to obtain two fragments of 2,284 and 6,487 bp, respectively, following enzyme digestion using Nhe I (catalog no. R0131S; New England BioLabs, Inc.) and Bsu36I (catalog no. R0524S; New England BioLabs, Inc.). For enzyme digestion, $\mathrm{PCR}$ products were digested with $\mathrm{XbaI}$ and Kpn I (10 U) or Nhe I and Bsu36I (10 U) for $\geq 3 \mathrm{~h}$ in $50 \mu \mathrm{l}$ and purified with the Qiagen PCR purification kit according to the manufacturer's protocol. For the ligation reactions, the purified vector and PCR fragments were incubated overnight at $16^{\circ} \mathrm{C}$ using T4 DNA ligase (Thermo Fisher Scientific, Inc., catalog no. EL0012). The insert: Vector ratio was 3:1. $1 \mu \mathrm{l}(400 \mathrm{U} / \mu \mathrm{l}) \mathrm{T} 4$ ligase and $2 \mu 110$ ligation buffer were used in a total volume of $20 \mu$ l. PDC316-hTERT and pDC316-G5E4T were constructed using the restriction enzymes in a total volume of $20 \mu \mathrm{l}$, as recommended by the manufacturer (New England BioLabs, Inc.) and ligation reactions with DNA ligase (Thermo Fisher Scientific, Inc., catalog no. EL0012). The shuttle plasmid pDC316-hTERT-Fas, pDC316-hTERT-GAL4VP2 and pDC316-G5E4T-Fas were also constructed. Construction of shuttle plasmids was performed as follows: The plasmid target sequence was used as a template, and primer pairs containing corresponding restriction enzyme sites were used to amplify the target sequence by PCR using Herculase II Fusion DNA Polymerase (Agilent Technologies, Inc., Santa Clara, CA, USA) (Table I). The PCR product of target sequence fragments was electrophoresed and collected using the Takara Agarose Gel DNA Purification kit (Takara Biotechnology Co., Ltd), and then ligated into the connection vector pMD18-T using Solution I of the Takara DNA Ligation kit (Takara Biotechnology Co., Ltd). The connection vector was used to transfect competent JM109 cells (Sigma Aldrich) using the Lipofectamine $^{\circledR} 3000$ (Invitrogen; Thermo Fisher Sceintific, Inc.) according to the manufacturer's protocol, and bacterial colonies were selected for clone culture. For verification of the target sequence of the pMD18-T vector, the RV-M sequence of 5'-GAG CGG ATA ACA ATT TCA CAC AGG-3' and the M13-47 sequence of 5'-CGC CAG GGT TTT CCC AGT CAC GAC-3' were used as primers to amplify positive clones by PCR. The obtained connection vector plasmid containing the target sequence was digested using restriction enzymes EcoRV (catalog no. R0195T, New England BioLabs, Inc.) and EcoR I, (catalog no. B0101S, New England BioLabs, Inc.) corresponding to the enzyme sites in the PCR primers, and 


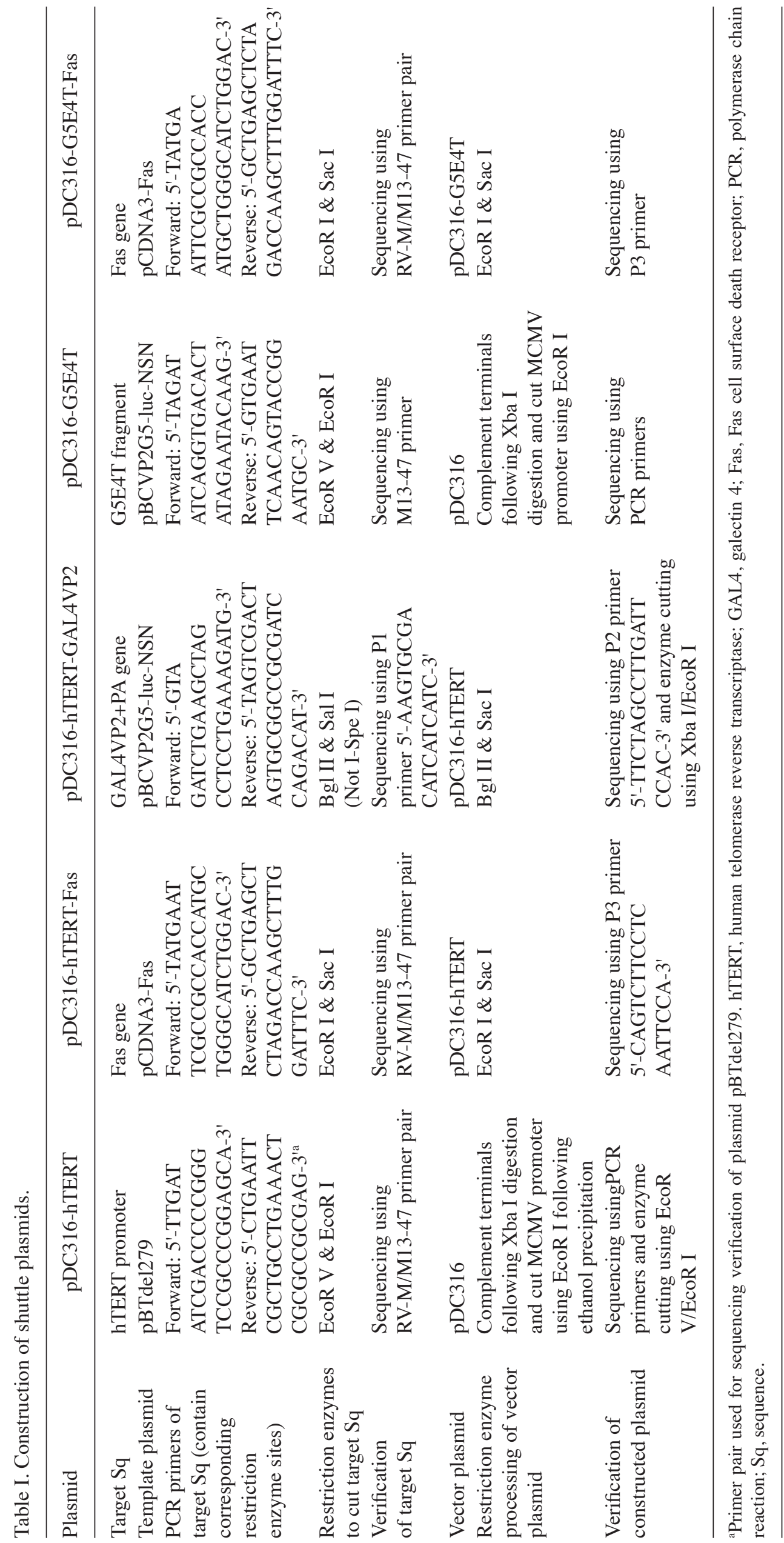


Table II. Summary of target gene identification, viral titer and TCID50 of 3 recombinant adenoviruses.

\begin{tabular}{|c|c|c|c|}
\hline Adenovirus & $\begin{array}{l}\text { Viral titer } \\
(\mathrm{VP} / \mathrm{ml})\end{array}$ & $\begin{array}{l}\text { Target gene } \\
\text { identification } \\
\text { by PCR }\end{array}$ & $\begin{array}{l}\text { TCID50 } \\
\text { (IU/ml) }\end{array}$ \\
\hline Ad5-htert-GAL4VP2 & $1.4 \times 10^{11}$ & Correct & $5.0 \times 10^{9}$ \\
\hline Ad5-htert-Fas & $3.8 \times 10^{11}$ & Correct & $3.9 \times 10^{9}$ \\
\hline Ad5-G5E4T-Fas & $2.7 \times 10^{11}$ & Correct & $5.6 \times 10^{9}$ \\
\hline
\end{tabular}

TCID50, tissue culture infective dose; PCR, polymerase chain reaction; hTERT, human telomerase reverse transcriptase; GAL4, galectin 4; Fas, Fas cell surface death receptor.

the target sequence was electrophoresed and collected. At the same time, the vector plasmid was digested using corresponding restriction enzymes ( $E c o R V$, catalog no. R0195T and EcoR I, catalog no. B0101S, New England BioLabs, Inc.), and then electrophoresed and collected. The target sequence was ligated into the vector plasmid using a DNA ligase enzyme (Sigma-Aldrich) and the constructed plasmid was transfected using Lipofectamine ${ }^{\circledR} 3000$ (Invitrogen; Thermo Fisher Scientific. Inc.) according to the manufacturer's protocol. The plasmid was collected following positive clone culture. For verification of the constructed plasmid, fragment PCR sequencing using Herculase II Fusion DNA Polymerase (Agilent Technologies) or enzyme digestion was used (using EcoRV, catalog no. R0195T and EcoR I, catalog no. B0101S, New England BioLabs, Inc.). The reaction conditions of PCR using a DNA polymerase were as follows: 1 cycle at $95^{\circ} \mathrm{C}$ for 5 mins; 5 cycles at $95^{\circ} \mathrm{C}$ for $30 \mathrm{sec}, 58^{\circ} \mathrm{C}$ for $45 \mathrm{sec}$ and $72^{\circ} \mathrm{C}$ for 3 mins; 35 cycles of $95^{\circ} \mathrm{C} 30 \mathrm{sec}, 95^{\circ} \mathrm{C}$ for $45 \mathrm{sec}, 72^{\circ} \mathrm{C}$ for 3 mins and a final extension at $72^{\circ} \mathrm{C}$ for 10 mins. The reaction conditions of enzyme digestion and ligation reactions were the same as above.

Adenoviral packaging and purification. The packaging and purification of the adenovirus vectors Ad5-hTERT-GAL4VP2, Ad5-hTERT-Fas and Ad5-G5E4T-Fas was performed using the AdEasy adenoviral vector system, according to the manufacturer's protocol. Briefly, HEK293 cells at 60-70\% confluence in fresh Dulbecco's modified Eagle's medium (Sigma Aldrich) containing 10\% fetal bovine serum (FBS; Invitrogen, Thermo Fisher Scientific, Inc.) were co-transfected with recombinant shuttle plasmids (pDC316-hTERT-Fas, pDC316-hTERT-GAL4VP2 or pDC316-G5E4T-Fas) or negative control plasmid (pDC316 empty vector) (Vigene Biosciences Inc., Rockville, MD, USA) and adenovirus backbone plasmid pBHGloxdelE13cre using Lipofectamine ${ }^{\circledR} 3000$ (Invitrogen; Thermo Fisher Scientific, Inc.) according to the manufacturer's protocol. The plaques were scraped off 7-10 days following transfection, collected by centrifugation $\left(5 \mathrm{mins}\right.$ at $7,000 \mathrm{xg}$ at $\left.1^{\circ} \mathrm{C}\right)$, and resuspended in PBS. The cell suspension was frozen in liquid nitrogen and thawed at $37^{\circ} \mathrm{C} 3$ times. The supernatant containing recombinant adenoviruses was collected by centrifugation at $3,000 \mathrm{xg}$ for $10 \mathrm{mins}$ at $4^{\circ} \mathrm{C}$. Adenovirus contained in the supernatant was filtered through $0.45 \mu \mathrm{m}$ filter and pooled with the buffer ( $40 \mathrm{mM}$ Tris, $2 \mathrm{mM} \mathrm{MgCl} 2$, $5 \%$ glycerol (v/v), $\mathrm{pH} 8.0)$ to obtain a homogeneous adenovirus stock for purification experiments. Chromatography was performed on an AKTA Basic low-pressure liquid chromatography system. The column was equilibrated with 2 column volumes (CV) loading buffer ( $40 \mathrm{mM}$ Tris, $2 \mathrm{mM}$ $\mathrm{MgCl}_{2}, 0.3 \mathrm{M} \mathrm{NaCl}, 5 \%$ glycerol (v/v), $\mathrm{pH} 8.0$ ) at a flow rate of $0.5 \mathrm{ml} / \mathrm{min}$. Injection of $100 \mu \mathrm{l}$ of sample was followed by a linear gradient of $0.3 \mathrm{M}$ to $1 \mathrm{M} \mathrm{NaCl}$ for $10 \mathrm{CV}$. The column was cleaned with $2 \mathrm{CV}$ of $0.5 \mathrm{M} \mathrm{NaOH}$ and then the recombinant adenoviruses were stored at $-20^{\circ} \mathrm{C}$ in buffer $(20 \mathrm{mM}$ Tris-HCl, pH 7.8, $75 \mathrm{mM} \mathrm{NaCl}, 2 \mathrm{mM} \mathrm{MgCl}{ }_{2}, 5 \%$ Trehalose, $0.0025 \%$ Tween- 80 in $11 \mathrm{ddH}_{2} \mathrm{O}$ ). The presence of the target gene in the recombinant adenoviruses was confirmed by PCR with Herculase II Fusion DNA Polymerase (Agilent Technologies), the viral titer and TCID50 of each viral stock was measured (Table II).

Transfection of adenovirus. The human ovarian carcinoma cell line SKOV3 and the control human embryonic lung fibroblast cell line HELF were transfected with recombinant adenoviruses using Lipofectamine ${ }^{\circledR} 3000$ (Invitrogen; Thermo Fisher Scientific, Inc.) according to the manufacturer's protocol. Briefly, SKOV3 and HELF cells at the exponential phase were digested with trypsin $(100 \mu \mathrm{g} / \mathrm{ml}$; Sigma Aldrich), collected by centrifugation $\left(5 \mathrm{~min}\right.$ at $1,000 \mathrm{x} \mathrm{g}$ on $4^{\circ} \mathrm{C}$ ), inoculated at a density of $8.0 \times 10^{5}$ cells/bottle in $25 \mathrm{~cm}^{2}$ flasks and incubated overnight at $37^{\circ} \mathrm{C}$ in an incubator with $5 \% \mathrm{CO}_{2}$. Cells were infected with $1 \mathrm{ml}$ adenoviral solution at a multiplicity of infection of $100 \mathrm{pfu} / \mathrm{cell}$. Three experimental groups were prepared including a blank control group cultivated in medium without viruses, a hTERT group transfected with Ad5-hTERT-Fas, and a TSTA group co-transfected with Ad5-hTERT-GAL4VP16 and Ad5-G5E4T-Fas.

Reverse transcription-quantitative PCR (RT-qPCR). Total RNA was extracted by the conventional TRIzol reagent (Invitrogen; Thermo Fisher Scientific, Inc.). The RNA extract was quantified using a spectrophotometer at 260 and $280 \mathrm{~nm}$. A ratio of OD260 to OD280 between 1.8 and 2.0 indicated clean RNA isolates. RNA was reverse transcribed into cDNA using using the Revert Aid First Strand cDNA Synthesis kit (Thermo Fisher Scientific, Inc., catalog no. K1622) following the manufacturer's protocol. The cDNA was then used as the template for PCR using a SYBR-Green PCR Master mix kit (Takara Biotechnology Co., Ltd., catalog no. RR820) and a Bio-Rad IQTM5 Multicolor Real-Time PCR Detection system (Bio-Rad Laboratories, Inc., Hercules, CA, USA). Cycling conditions were as follows: $95^{\circ} \mathrm{C}$ for $30 \mathrm{sec}$, followed by 40 cycles of $95^{\circ} \mathrm{C}$ for $5 \mathrm{sec}$ and $60^{\circ} \mathrm{C}$ for $34 \mathrm{sec}$. Primer sequences were as follows: Forward, 5'-TGC CCA AGT GAC TGA CAT CAA-3' and reverse, 5'-GCC ATG TCC TTC ATC ACA CAA-3' for Fas; forward, 5'-AAC CCT AAG GCC AAC CGT GAA-3' and reverse, 5'-TGT CAC GCA CGA TTT CCC TCT-3' for $\beta$-actin. Relative target gene expression was quantified according to the $2^{-\Delta \Delta C a}$ method and normalized to $\beta$-actin as an endogenous control (5). Data are expressed as the mean \pm standard deviation of three independent experiments. 
1

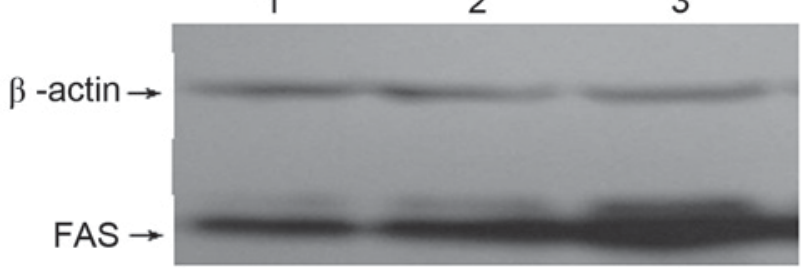

Figure 1. Western blot analysis of Fas cell surface death receptor expression in SKOV3 cells in different transfection groups: 1, blank control group; 2, human telomerase reverse transcriptase group and 3, two-step transcriptional amplification system group.

Western blot analysis. The expression of Fas protein was determined by western blot analysis. Briefly, cells at the exponential phase were collected and lysed with radioimmunoprecipitation assay buffer containing a protease inhibitor cocktail (Sigma-Aldrich) for $10 \mathrm{~min}$ at $4^{\circ} \mathrm{C}$. Total protein was collected by centrifugation $\left(12,000 \mathrm{x}\right.$ g for $15 \mathrm{mins}$ at $\left.4^{\circ} \mathrm{C}\right)$, and quantified using a bicinchoninic acid assay kit (Thermo Fisher Scientific, Inc.) according to the manufacturer's protocol. Equal amounts of total protein $(50 \mu \mathrm{g})$ were separated by SDS-PAGE electrophoresis and transferred to polyvinylidene difluoride membranes at $200 \mathrm{~mA}$ for $6 \mathrm{~h}$. The membrane was blocked in TBS buffer containing 5\% skim milk and $0.1 \%$ Tween-20 at room temperature for $2 \mathrm{~h}$, and incubated with the appropriate primary antibody overnight at $4^{\circ} \mathrm{C}$. The membrane was washed and incubated with peroxidase-labeled goat anti-mouse secondary antibodies $(1: 10,000$, catalog no. 7074; Cell Signaling Technology, Inc., Danvers, MA, USA) at room temperature for $1 \mathrm{~h}$. The membranes were washed 3 times with TBST for $5 \mathrm{~min}$. The results were analyzed using an Enhanced Chemiluminescence substrate kit and the Enhanced Chemiluminescence Detection system (GE Healthcare, Chicago, IL, USA). The antibodies used were mouse anti-human Fas monoclonal antibody (Abcam; catalog no. $15285 ; 1: 500)$ and $\beta$-actin monoclonal antibody (Abcam; catalog no. ab8226; 1:1,000).

Isolation and phenotypic identification of human peripheral blood lymphocytes $\gamma \delta T$. The present study was approved by the Liuzhou Maternal and Child Health Hospital Institutional Review Board (Liuzhou, China) and written, informed consent was provided by all participants. Fresh peripheral blood $(30 \mathrm{ml})$ was collected from healthy women and mixed with lymphocyte separation medium (Sigma-Aldrich). Cells were collected by centrifugation $\left(1,500 \mathrm{x}\right.$ g for $20 \mathrm{mins}$ at $\left.4^{\circ} \mathrm{C}\right)$, washed and inoculated into 24 -well plates. An appropriate amount of IL-2 was added to each well for a final concentration of $200 \mathrm{U} / \mathrm{ml}$. The medium was replaced with fresh medium every 3-4 days until the mononuclear cells reached the exponential phase, at 10-12 days. $\gamma \delta \mathrm{T}$ cells with the desired phenotype were collected and diluted for a density of $1 \times 10^{7}$ cells $/ \mathrm{ml}$ with RPMI 1640 medium (Invitrogen; Thermo Fisher Scientific, Inc.) supplemented with $10 \%$ FBS (Invitrogen; Thermo Fisher Scientific, Inc.) for subsequent experiments. The phenotype of isolated cells was analyzed by flow cytometry. For flow cytometry, monocyte markers were stained with anti-human FasL-IgG1 monoclonal antibody (dilution, 1:150; eBioscience, Thermo Fisher Scientific, Inc., catalog no. MA5-17073) for
$30 \mathrm{~min}$ at $37^{\circ} \mathrm{C}$, and blood was lysed with $0.87 \%$ ammonium chloride (Beckman Coulter, Inc., Brea, CA, USA) for $12 \mathrm{~min}$ at room temperature, washed twice with PBS, and fixed with a $100 \%$ methanol-based reagent for $10 \mathrm{~min}$ at $4^{\circ} \mathrm{C}$. The cells were suspended in a tube with a binding buffer $(300 \mathrm{ml})$ and $5 \mathrm{ml}$ Annexin V-fluorescein isothiocyanate (Nanjing KeyGen Biotech Co., Ltd., Nanjing, China) were added for cell labeling at room temperature in the dark for $15 \mathrm{~min}$. The samples were analyzed using a FACSCalibur flow cytometer (BD Biosciences, Franklin Lakes, NJ, USA) and FlowJo version 9.1 software (TreeStar, Inc., Ashland, Oregon).

Killing activity of $\gamma \delta T$ cells against SKOV3 cells. The $\gamma \delta \mathrm{T}$ cell-mediated killing activity against SKOV3 cells with different Fas expression was assessed. Briefly, SKOV3 cells from the blank control, hTERT and TSTA groups were used as target cells. These cells were inoculated into 96-well plates at a density of $1 \times 10^{5}$ cells/well. $\gamma \delta \mathrm{T}$ cells were added at an effector-target cell ratio of 5:1, 10:1, 20:1 and 40:1, respectively. The plates were incubated at $37^{\circ} \mathrm{C}$ for $6 \mathrm{~h}$ in an incubator, and Cell Counting Kit- 8 reagent (10 $\mu 1$, Beyotime Institute of Biotechnology, Haimen, China) was added to each well. The plates were incubated for an additional $2 \mathrm{~h}$, and optical density was measured at $450 \mathrm{~nm}$. The killing rate was calculated using the following formula: [OD450 of target cell control-(OD450 of experimental well-OD450 of effector cell control)]/target cell controlx $100 \%$.

Killing activity of $\gamma \delta$ T cells blocked with FasL-IgG1 monoclonal antibody. $\gamma \delta \mathrm{T}$ cells $\left(1 \mathrm{ml} ; 1 \times 10^{7}\right.$ cells $\left./ \mathrm{ml}\right)$ were incubated with $100 \mu \mathrm{l}$ anti-human FasL-IgG1 monoclonal antibody ( $10 \mu \mathrm{g}$, dilution: $1: 100)$ at $37^{\circ} \mathrm{C}$ for $2 \mathrm{~h} . \gamma \delta \mathrm{T}$ cells were collected as effector cells, and their killing activity against SKOV3 cells was determined as described above.

\section{Results}

RT-qPCR analysis of Fas mRNA expression. The expression of Fas mRNA in SKOV3 and HELF cells in different transfection groups was compared by RT-qPCR. Fas mRNA expression in SKOV3 cells in TSTA group co-transfected with Ad5-hTERT-GAL4VP16 and Ad5-G5E4T-Fas was 14.2 times higher than in the blank control group (Table III). Fas mRNA expression in HELF cells in the TSTA group was 3.7 times higher compared with the blank control group (Table III).

Western blot analysis of Fas protein expression. The expression of Fas protein in SKOV3 cells in different transfection groups was compared by western blot analysis. The expression of Fas protein was highest in the TSTA group, followed by the hTERT group, with the lowest Fas expression detected in the blank control group (Fig. 1).

$\gamma \delta T$ cell-mediated killing against SKOV3 cells. The killing effect of $\gamma \delta \mathrm{T}$ cells against SKOV3 cells transfected with adenoviruses expressing Fas was evaluated at different effector to target cell ratios. The killing rate was higher with increased Fas expression in SKOV3 cells (Table IV). The killing activity was also stronger at a higher effector to target cell ratio. The highest killing rate $(72.5 \%)$ was observed in 
Table III. Comparison of Fas mRNA expression in SKOV3 and HELF cells in different transfection groups.

\begin{tabular}{lrc}
\hline Transfection group & Fas mRNA copies & Fold of increase \\
\hline SKOV3 & & \\
Blank control & 927.1 & 1.0 \\
hTERT & 2389.1 & 2.6 \\
TSTA & 13174.4 & 14.2 \\
HELF & & \\
Blank control & 105.6 & 1.0 \\
hTERT & 154.7 & 1.5 \\
TSTA & 387.6 & 3.7 \\
\hline
\end{tabular}

Fas, Fas cell surface death receptor; hTERT, human telomerase reverse transcriptase; TSTA, two-step transcriptional amplification system.

Table IV. $\gamma \delta$ T cell-mediated killing effect against SKOV3 cells at different effector to target cell ratios.

\begin{tabular}{|c|c|c|c|c|}
\hline \multirow[b]{2}{*}{ Parameter } & \multicolumn{4}{|c|}{ Effector to target cell ratio } \\
\hline & $5: 1$ & $10: 1$ & $20: 1$ & $40: 1$ \\
\hline \multicolumn{5}{|c|}{$\begin{array}{l}\text { OD450 (following } \\
\text { calibration }\end{array}$} \\
\hline SKOV3 & 1.858 & 1.858 & 1.858 & 1.858 \\
\hline$\gamma \delta \mathrm{T}$ & 0.158 & 0.302 & 0.608 & 1.197 \\
\hline $\mathrm{SKOV} 3+\gamma \delta \mathrm{T}$ & 1.914 & 2.206 & 2.161 & 2.483 \\
\hline hTERT & 1.691 & 1.691 & 1.691 & 1.691 \\
\hline hTERT $+\gamma \delta \mathrm{T}$ & 1.670 & 1.609 & 1.711 & 1.934 \\
\hline TSTA & 1.672 & 1.672 & 1.672 & 1.672 \\
\hline $\mathrm{TSTA}+\gamma \delta \mathrm{T}$ & 1.616 & 1.494 & 1.569 & 1.657 \\
\hline \multicolumn{5}{|l|}{ Killing rate $(\%)$} \\
\hline SKOV3 & - & - & - & - \\
\hline$\gamma \delta \mathrm{T}$ & - & - & - & - \\
\hline SKOV $3+\gamma \delta \mathrm{T}$ & 5.5 & 7.2 & 16.4 & 30.8 \\
\hline hTERT & - & - & - & - \\
\hline hTERT $+\gamma \delta \mathrm{T}$ & 10.6 & 22.9 & 34.8 & 56.4 \\
\hline TSTA & - & - & - & - \\
\hline $\mathrm{TSTA}+\gamma \delta \mathrm{T}$ & 12.8 & 28.7 & 42.5 & 72.5 \\
\hline
\end{tabular}

OD, optical density; hTERT, human telomerase reverse transcriptase; TSTA, two-step transcriptional amplification system.

the TSTA group at an effector to target cell ratio of 40:1 (Table IV).

Killing effects of FasL-IgG1-blocked $\gamma \delta T$ cells against SKOV3 cells. $\gamma \delta \mathrm{T}$ cells were blocked with anti-human FasL-IgG1 monoclonal antibody, and the killing effects against SKOV3 cells from different transfection groups was compared. The killing activity of FasL-IgG1-blocked $\gamma \delta$ T cells was markedly reduced (Table V). The killing rate of FasL-IgG1-blocked
Table V. Killing effects of FasL-IgG1-blocked $\gamma \delta \mathrm{T}$ cells against SKOV3 cells at different effector to target cell ratios.

\begin{tabular}{|c|c|c|c|c|}
\hline \multirow[b]{2}{*}{ Parameter } & \multicolumn{4}{|c|}{ Effector to target cell ratio } \\
\hline & $5: 1$ & $10: 1$ & $20: 1$ & $40: 1$ \\
\hline \multicolumn{5}{|c|}{ OD450 (following } \\
\hline SKOV3 & 1.843 & 1.843 & 1.843 & 1.843 \\
\hline$\gamma \delta \mathrm{T}$ & 0.148 & 0.303 & 0.598 & 1.156 \\
\hline SKOV $3+\gamma \delta \mathrm{T}$ & 1.956 & 2.089 & 2.283 & 2.724 \\
\hline hTERT & 1.674 & 1.674 & 1.674 & 1.674 \\
\hline hTERT $+\gamma \delta \mathrm{T}$ & 1.727 & 1.779 & 2.018 & 2.388 \\
\hline TSTA & 1.668 & 1.668 & 1.668 & 1.668 \\
\hline $\mathrm{TSTA}+\gamma \delta \mathrm{T}$ & 1.703 & 1.749 & 1.974 & 2.330 \\
\hline \multicolumn{5}{|l|}{ Killing rate $(\%)$} \\
\hline SKOV3 & - & - & - & - \\
\hline$\gamma \delta \mathrm{T}$ & - & - & - & - \\
\hline SKOV $3+\gamma \delta \mathrm{T}$ & 1.9 & 3.1 & 8.6 & 14.9 \\
\hline hTERT & - & - & - & - \\
\hline hTERT $+\gamma \delta \mathrm{T}$ & 5.7 & 11.8 & 15.2 & 26.4 \\
\hline TSTA & - & - & - & - \\
\hline $\mathrm{TSTA}+\gamma \delta \mathrm{T}$ & 6.8 & 13.3 & 17.5 & 29.6 \\
\hline
\end{tabular}

FasL, Fas cell surface death receptor ligand; IgG, immunoglobulin G; OD, optical density; hTERT, human telomerase reverse transcriptase; TSTA, two-step transcriptional amplification system.

$\gamma \delta$ T cells was only $29.6 \%$ at an effector to target cell ratio of 40:1 (Table V).

\section{Discussion}

At present, low expression of exogenous genes at target sites is one of the major issues in tumor gene therapy $(6,7)$. TSPs have been frequently used in the expression vector system in order for efficient targeted expression of exogenous genes in cancer cells $(8,9)$. To date, several promoters that initiate the targeted expression of exogenous genes have been identified, including SLPI, OSP1, HES1 and hTERT $(10,11)$. Nevertheless, most of these promoters are neither ovarian cancer-specific nor epithelial-specific, including SLPI, OPSI and hESEI. Theoretically, among all TSPs, hTERT promoter is more likely to be efficient in gene therapy for ovarian cancer because telomerase has relatively high activity in ovarian cancer cells, but low activity in normal cells including ovarian epithelial cells. Furthermore, hTERT promoter is only activated in telomerase-positive tumor cells, but is not active in normal telomerase-negative cells $(12,13)$. Nevertheless, the activity of tissue-specific promoters, including the hTERT promoter, is often too low for effective targeted gene therapy. Several strategies have been used to enhance the activity of these promoters including point mutations in the promotor region, deletion mutations removing the parts with transcriptional inefficiency, chimeric promoters formed by the fusion of efficient parts from different promoters, regulation at the post-transcriptional level, and 
the use of recombinant transcriptional activator (RTA). In a previous study, RTAs have been used to improve the activity of TSPs (14). The TSTA system contains a transcriptional activator GAL4-VP16 and a G5E4T regulatory element, a small promoter that is responsive to GAL4, and has enhanced the activities of the corresponding TSP $(15,16)$. It has been demonstrated that the expression of firefly luciferase gene (f1) and mutant HSV1 thymidine kinase gene in prostate cancer cells with a TSTA system was increased by 50 and 12 times, respectively, compared with control cells without the system (17). However, the efficiency of the TSTA system is associated with different TSPs and target genes.

In the present study, recombinant adenoviruses carrying an hTERT promoter that regulated the expression of Fas and a TSTA system were successfully constructed in order to achieve high expression levels of the target gene in cancer cells, but low or no expression in noncancerous cells. Although Fas mRNA and protein were expressed in SKOV3 and normal control HELF cells transfected with the constructed adenoviruses, the level of Fas expression in SKOV3 cells was higher than in HELF cells, suggesting that the hTERT promoter initiated ovarian cancer-specific Fas expression and the TSTA system further enhanced the gene expression by improving the activity of the promoter. In a previous study, the TSTA system containing the modified chimeric transcriptional activator GAL4VP2 and the target $\mathrm{f} 1$ gene was constructed in a single or in two different adenoviral vectors (16). It was revealed that the 11 expression in cells transfected with two adenoviral vectors was higher compared with single adenoviral group (18-20). In the present study, a similar approach of co-transfection of two different adenoviral vectors was used. However, the expression of Fas in the co-transfection group was only increased by 7 fold compared with the hTERT single adenoviral group, which may be associated with low activity of the hTERT promoter or the low transfection efficiency of adenovirus in the target SKOV3 cells.

Cytotoxic T lymphocytes (CTLs) and natural killer cells serve an important function in the immune system. The anti-tumor effects of CTL cells are achieved by direct lysis or apoptotic induction of target cells. Depending on the $\mathrm{T}$ cell receptor (TCR), T lymphocytes can be divided into $\mathrm{TCR}_{\alpha \beta}$ and TCR $\mathrm{T}_{\gamma \delta}$ cells. $\gamma \delta \mathrm{T}$ cells directly bind to antigens, including polypeptides and lipids, due to their rich surface FasL, and thus effectively target Fas-expressing tumor cells, which initiates the Fas/FasL apoptotic pathway (21-23). In the present study, the killing activity of effector $\gamma \delta \mathrm{T}$ cells against SKOV3 cells was increased with higher effector to target cell ratios. The killing effect was also stronger in SKOV3 cells with higher expression of Fas, which suggested that enhancing the killing effect of immune cells by the upregulation of Fas expression in tumor cells may be a feasible approach for efficient cancer gene therapy. Furthermore, the killing activity of $\gamma \delta$ T cells blocked with anti-human FasL-IgG1 monoclonal antibody against SKOV3 cells was reduced. Nevertheless, these $\gamma \delta$ T cells still exhibited a certain degree of killing activity, as indicated by the clear oncolysis that was observed (data not shown). These results suggested that $\gamma \delta$ T cells killed ovarian cancer cells by direct lysis and apoptotic induction.
In conclusion, the regulators of hTERT promoter and TSTA assured efficient and targeted expression of their downstream Fas gene in SKOV3 cells. The killing effect of $\gamma \delta \mathrm{T}$ cells against ovarian cancer cells with high Fas expression was improved. The present study thus sheds light on a potential effective targeted gene therapy for ovarian cancer.

\section{References}

1. Chira S, Jackson CS, Oprea I, Ozturk F, Pepper MS, Diaconu I, Braicu C, Raduly LZ, Calin GA and Berindan-Neagoe I: Progresses towards safe and efficient gene therapy vectors. Oncotarget 6: 30675-30703, 2015.

2. Ryu CJ, Whitehurst CE and Chen J: Expression of Gal4-VP16 and Gal4-DNA binding domain under the control of the $\mathrm{T}$ lymphocyte-specific lck proximal promoter in transgenic mice. BMB Rep 41: 575-580, 2008.

3. Yamashita Y: Ovarian cancer: New developments in clear cell carcinoma and hopes for targeted therapy. Jpn J Clin Oncol 45: 405-407, 2015.

4. Guillermo LV, Silva EM, Ribeiro-Gomes FL, De Meis J, Pereira WF, Yagita H, DosReis GA and Lopes MF: The Fas death pathway controls coordinated expansions of type 1 CD8 and type 2 CD4 T cells in Trypanosoma cruzi infection. J Leukoc Biol 81: 942-951, 2007.

5. Livak KJ and Schmittgen TD: Analysis of relative gene expression data using real-time quantitative PCR and the 2(-Delta Delta C(T)) method. Methods 25: 402-408, 2001.

6. Keswani R, Su K and Pack DW: Efficient in vitro gene delivery by hybrid biopolymer/virus nanobiovectors. J Control Release 192: 40-46, 2014.

7. Parhiz H, Shier WT and Ramezani M: From rationally designed polymeric and peptidic systems to sophisticated gene delivery nano-vectors. Int J Pharm 457: 237-259, 2013.

8. Ghosh SS, Takahashi M, Thummala NR, Parashar B, Chowdhury NR and Chowdhury JR: Liver-directed gene therapy: Promises, problems and prospects at the turn of the century. J Hepatol 32 (1 Suppl): S238-S252, 2000.

9. Singh HM, Ungerechts G and Tsimberidou AM: Gene and cell therapy for pancreatic cancer. Expert Opin Biol Ther 15: 505-516, 2015.

10. Wolf JK and Jenkins AD: Gene therapy for ovarian cancer (review). Int J Oncol 21: 461-468, 2002.

11. Bauknecht T and Meinhold-Heerlein I: Gene therapy of ovarian cancer. Curr Womens Health Rep 2: 39-46, 2002.

12. Riesco-Eizaguirre G, De la Vieja A, Rodríguez I, Miranda S, Martín-Duque P, Vassaux G and Santisteban P:Telomerase-driven expression of the sodium iodide symporter (NIS) for in vivo radioiodide treatment of cancer: A new broad-spectrum NIS-mediated antitumor approach. J Clin Endocrinol Metab 96: E1435-E1443, 2011.

13. Song JS, Kim HP, Yoon WS, Lee KW, Kim MH, Kim KT, Kim HS and Kim YT: Adenovirus-mediated suicide gene therapy using the human telomerase catalytic subunit (hTERT) gene promoter induced apoptosis of ovarian cancer cell line. Biosci Biotechnol Biochem 67: 2344-2350, 2003.

14. Craig NJ and Maffulli N: Subtrochanteric fractures: Current management options. Disabil Rehabil 27: 1181-1190, 2005.

15. Song Y, Xin X, Xia Z, Zhai X and Shen K: Selective suppression of autocatalytic caspase-3 driven by two-step transcriptional amplified human telomerase reverse transcriptase promoter on ovarian carcinoma growth in vitro and in mice. Oncol Rep 32: 225-234, 2014.

16. Iyer M, Salazar FB, Lewis X, Zhang L, Wu L, Carey M and Gambhir SS: Non-invasive imaging of a transgenic mouse model using a prostate-specific two-step transcriptional amplification strategy. Transgenic Res 14: 47-55, 2005.

17. Iyer M, Wu L, Carey M, Wang Y, Smallwood A and Gambhir SS: Two-step transcriptional amplification as a method for imaging reporter gene expression using weak promoters. Proc Natl Acad Sci USA 98: 14595-14600, 2001.

18. Sato M, Johnson M, Zhang L, Zhang B, Le K, Gambhir SS, Carey $\mathrm{M}$ and Wu L: Optimization of adenoviral vectors to direct highly amplified prostate-specific expression for imaging and gene therapy. Mol Ther 8: 726-737, 2003. 
19. Sato M, Figueiredo ML, Burton JB, Johnson M, Chen M Powell R, Gambhir SS, Carey M and Wu L: Configurations of a two-tiered amplified gene expression system in adenoviral vectors designed to improve the specificity of in vivo prostate cancer imaging. Gene Ther 15: 583-593, 2008.

20. Jiang ZK, Sato M and Wu L: Chapter five-The development of transcription-regulated adenoviral vectors with high cancer-selective imaging capabilities. Adv Cancer Res 115: 115-146, 2012.

21. Merritt RE, Mahtabifard A, Yamada RE, Crystal RG and Korst RJ: Cisplatin augments cytotoxic T-lymphocyte-mediated antitumor immunity in poorly immunogenic murine lung cancer. J Thorac Cardiovasc Surg 126: 1609-1617, 2003.
22. Park IJ, Kim MJ, Park OJ, Park MG, Choe W, Kang I, Kim SS and Ha J: Cryptotanshinone sensitizes DU145 prostate cancer cells to Fas(APO1/CD95)-mediated apoptosis through Bcl-2 and MAPK regulation. Cancer Lett 298: 88-98, 2010.

23. Habib HM, Taher TE, Isenberg DA and Mageed RA: Enhanced propensity of $\mathrm{T}$ lymphocytes in patients with systemic lupus erythematosus to apoptosis in the presence of tumour necrosis factor alpha. Scand J Rheumatol 38: 112-120, 2009. 